\title{
Reinforcement of a PMMA resin for fixed interim prostheses with nanodiamonds
}

\author{
Popi PROTOPAPA ${ }^{1}$, Eleana KONTONASAKI ${ }^{1}$, Dimitrios BIKIARIS ${ }^{3}$, Konstantinos M. PARASKEVOPOULOS ${ }^{2}$ \\ and Petros KOIDIS ${ }^{1}$
}

\author{
${ }^{1}$ Department of Fixed Prostheses and Implants Prosthodontics, School of Dentistry, Aristotle University of Thessaloniki, GR-541 24, Thessaloniki, \\ Macedonia, Greece \\ ${ }^{2}$ Solid State Physics Section, School of Physics, Aristotle University of Thessaloniki, GR-541 24, Thessaloniki, Macedonia, Greece \\ ${ }^{3}$ Laboratory of Polymer Chemistry and Technology, Department of Chemistry, Aristotle University of Thessaloniki, GR-541 24, Thessaloniki, \\ Macedonia, Greece \\ Corresponding author, Konstantinos M. PARASKEVOPOULOS; E-mail: kpar@auth.gr
}

\begin{abstract}
The aim of this study was to investigate the possible reinforcement of Nanodiamonds (ND) in a PMMA resin for fixed interim restorations. The fracture toughness $\left(\mathrm{K}_{\mathrm{Ic}}\right)$, impact strength and the dynamic thermomechanical properties $\left(\mathrm{T}_{\mathrm{g}}, \mathrm{E}^{\prime}, \mathrm{E}^{\prime \prime}\right.$, tan $\left.\delta\right)$ of a series of PMMA-ND nanocomposites with different amounts of ND were evaluated. The fracture toughness increased as the ND percentage increased up to $0.38 \%$ wt but a greater amount of ND induced a decrease in $\mathrm{K}_{\mathrm{Ic}}$. Impact strength and Young's modulus were also increased by increasing nanoparticles content, indicating the reinforcing effect of ND. Dynamic mechanical properties were also affected. By increasing the ND content an increase of storage modulus was recorded, while glass transition was shifted at higher temperatures. Under the limitations of this study, it can be suggested that reinforcing PMMA with ND nanoparticles - especially at low concentrations- may increase the overall performance of fixed interim prostheses.
\end{abstract}

Keywords: Polymethyl methacrylate, Dental fixed interim prostheses, Nanocomposites, Nanodiamonds, Reinforcement

\section{INTRODUCTION}

Interim restorations are essential in fixed prosthodontics as they provide temporary protection of teeth prepared for fixed prostheses. Although the final prosthesis is usually placed after a short time, usually two weeks, in several instances factors related to patients or to laboratory procedures may contribute to significant prolongation. Furthermore, in complex prosthodontic treatments interim restorations have to remain in place for months for either diagnostic or therapeutic purposes ${ }^{11}$. In all these cases interim restorations have to retain structural and functional performance and integrity in order to meet patients' needs and dentists' expectations.

Autopolymerized polymethyl methacrylate (PMMA) resins have been widely used in the fabrication of interim fixed restorations. They should attain adequate strength in order to withstand occlusal forces. Furthermore, the resistance of these materials to crack initiation and propagation is important considering the time related performance of the restorations. However, in many patients, occlusal forces cause stresses especially in the marginal area of connectors that may exceed the elastic limit of the materials leading to deformation or fracture and eventually to failure ${ }^{2-4}$. Reinforcement of provisional resins has been attempted through various materials such as metal wires, fibers (glass, aramid and carbon graphite fibers) and various oxides (aluminum, zirconium, titanium and magnesium oxides $)^{5-10)}$. The chemical bond between the reinforcing agent and the

Color figures can be viewed in the online issue, which is available at J-STAGE.

Received Aug 25, 2010: Accepted Nov 26, 2010

doi:10.4012/dmj.2010-135 JOI JST.JSTAGE/dmj/2010-135 polymer matrix has to be strong enough to withstand and transmit occlusal forces from the weaker polymer to the stronger reinforcing agent. Furthermore, the uniform dispersion and impregnation of the reinforcing agent in the matrix prevents the development of areas that can act as stress concentrators and may impair the mechanical properties of the resins ${ }^{11}$.

Nanodiamonds (ND), also known as ultrafinedispersed diamonds (UDDs) or detonation nanodiamonds, are becoming one of the most widely studied nanomaterials due to their unique properties such as hardness, thermal conductivity, dopability or optical transparency over a wide spectral range ${ }^{12-14}$. ND powder can be produced by a detonation synthesis in large volumes and is a carbon nanomaterial for a broad range of potential applications, including composites ${ }^{13-16)}$. As produced powder consists of disordered graphite $(67 \%$ $\mathrm{wt})$ and diamond $(33 \% \mathrm{wt})$ and presents a mean diameter of $1-5 \mathrm{~nm}$, a specific surface of $300-590 \mathrm{~m}^{2} / \mathrm{g}$ and a specific gravity of $1.86 \mathrm{~g} / \mathrm{cm}^{3,16-18)}$. Although the physical and chemical properties of ND are highly affected by a series of parameters that differ among the manufacturers such as the explosive mixture, the coolant media and most importantly, the consequent purification of the detonation soot, all ND particles present numerous oxygen-containing hydrophilic chemical groups that make them attractive for various biomedical applications ${ }^{19,20)}$. Considering that the application of nanoparticles as fillers in polymeric matrices has shown encouraging results in the strengthening of the materials ${ }^{11,21)}$ it could be expected that the incorporation of ND nanoparticles into dental polymeric materials 
could have an enhancing effect on the mechanical properties of the resulting nanocomposites. Although the efficiency of using ND in polymeric materials has been suggested $^{22-25)}$ some controversial findings however have been reported in literature and were attributed mainly to the interactions between the nanoparticles themselves, which tended to form agglomerates which acted as points of stress concentration ${ }^{13,26,27)}$.

The aim of this work was to study the reinforcement effect of ND in an autopolymerizing PMMA resin used for the fabrication of interim fixed restorations. The major null hypothesis was that fracture toughness (F.T.) and impact strength (I.S.) of PMMA-ND composite specimens of various weight ratios would have no statistically significant different mean values compared to control PMMA.

\section{MATERIALS AND METHODS}

\section{Materials}

An autopolymerized PMMA acrylic resin for interim restorations (Jet, Lang Dental Mfg, Co., Inc., Chicago, Ill, USA) was used in all experiments. ND synthesis was described in US Patent 5.353.708 ${ }^{17}$. The as-produced nanodiamonds had average particle size of 4-6 $\mathrm{nm}$ and a specific surface area of about $400 \mathrm{~m}^{2} / \mathrm{g}$. However, after the nanodiamond purification, the particles obtained formed clusters with a size of $20-60 \mathrm{~nm}$.

Fracture toughness (Three-point bending test) and impact strength (Izod impact test)

The single-edge notched method was used to evaluate fracture toughness. 20 specimens for each group were fabricated according to the British Standard BS EN ISO 12737:2005 ${ }^{28)}$. Standardized rectangular specimens $3 \times 6$ $\times 25 \mathrm{~mm}$ with a pre-crack (notch) perpendicular to the specimen length with a depth of $3 \mathrm{~mm}$ were fabricated in a custom-made articulating stainless steel mold consisting of three parts (Fig. 1(a)) and loaded for flexural strength test (Fig. 1(b)).

Nano-composite specimens were fabricated by mixing the resin powder with a solution of monomer in which the ND nanoparticles were dispersed by excessive stirring at 800rpm for 10 minutes under sonication. The ND powder was pre-weighted in order to get $0.10 \%$, $0.38 \%, 0.50 \%$, and $0.83 \%$ wt. ND content in relation to PMMA powder. Consequently, the tested groups were PMMA-ND composites (PMMA-ND 0.10\%, PMMA-ND 0.38\%, PMMA-ND 0.50\% and PMMA-ND 0.83\%) while pure PMMA resin specimens served as controls (controlPMMA). For all specimens the optimum powder-liquid ratio was set to $2.5 \mathrm{~g} / 1.5 \mathrm{~mL}$ according to the literature ${ }^{29,30)}$. This powder liquid ratio provided adequate working time and had a flowable consistency that facilitated the insertion of the mixtures into the mold avoiding air entrapment. Each mixture was hand mixed for 30 seconds and immediately transferred to an applicator syringe for placement into the assembled mold which was sprayed with a thin film of lubricant (Slide, FarenIndustrie chimiche spA, Milano, Italy). The mold was slightly overfilled and the surface covered with a plastic matrix strip (KerrHawe Striproll Art No 686, KerrHawe SA, Bioggio, Switzerland) and a thick glass plate. After 30 seconds hand pressure on the glass plate, the specimens were left to polymerize for 7 minutes in an incubator at $37^{\circ} \mathrm{C}$. After that, the mold was disassembled and the resin specimen was removed. Optical inspection was performed in order to discard specimens with voids and bubbles. Consequently, 15 appropriate specimens from the control, the PMMA-ND $0.10 \%$ and the (a)
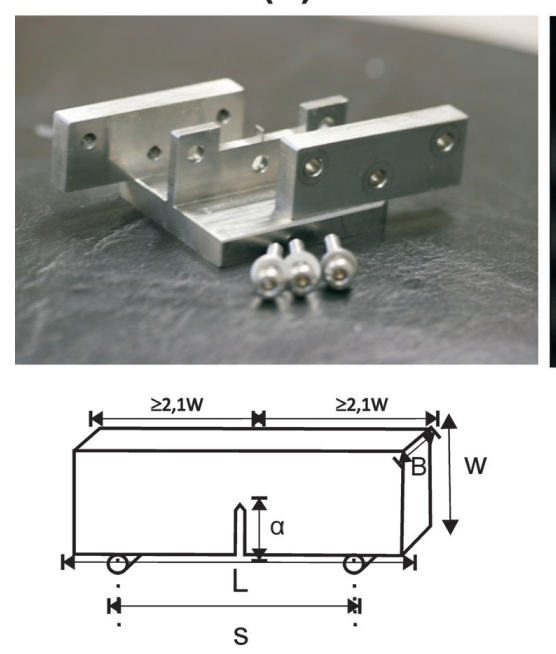

(b)
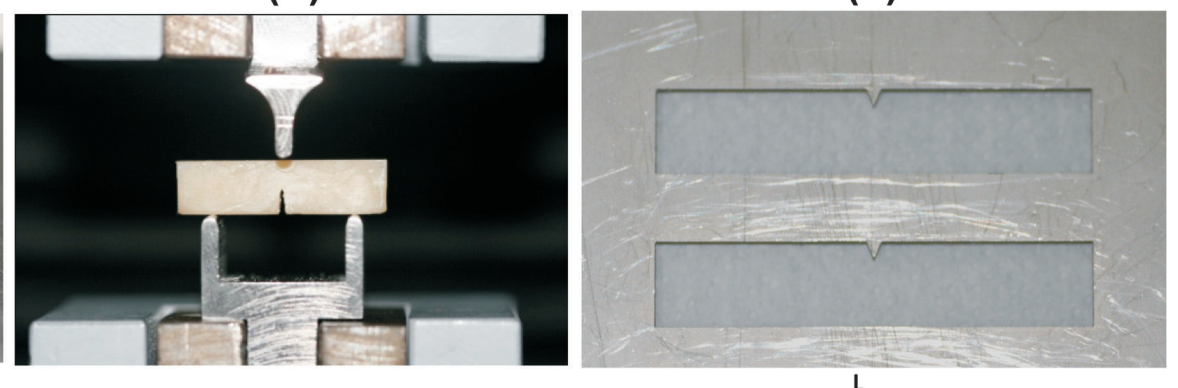

L

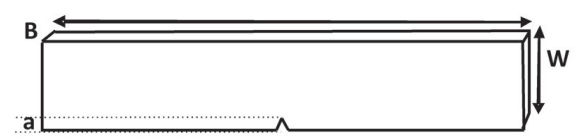

Fig. 1 (a) Stainless steel mold assembly and drawing of the specimens' configuration, (b) loading for fracture toughness test. $\mathrm{L}=$ specimens' length, $\mathrm{W}=$ specimens' height, $\mathrm{B}=$ specimens' width, $\mathrm{S}=$ span length, $\alpha=$ crack length and (c) Stainless steel mold assembly and drawing of the specimens' configuration for impact strength test, L=specimens' length, W=specimens' height, $\mathrm{B}=$ specimens' width, $\mathrm{a}=$ crack length. 
PMMA-ND $0.38 \%$ group and 18 from the PMMA-ND $0.50 \%$ and the PMMA-ND $0.83 \%$ group were included in the experiments. The specimens were stored in distilled water at $37^{\circ} \mathrm{C}$ for $24 \mathrm{~h}$ and were loaded for the 3-point bending test with a crosshead speed of $1 \mathrm{~mm} / \mathrm{min}$ until fracture using a universal testing machine (Instron 3344, Instron Corp., Canton, Mass., USA). Peak load to fracture, and specimen deflection (recorded as load/ deflection curves) were recorded, and fracture toughness $\left(\mathrm{K}_{\mathrm{Ic}}\right)$, was measured in $\mathrm{MPa} \cdot \mathrm{m}^{1,2,28)}$.

For the impact strength test, 8 specimens for each group were prepared according to ASTM D256 ${ }^{31}$, following the same procedure for the fabrication of the composites as reported before, in rectangular metallic molds of $64 \times 13 \times 3 \mathrm{~mm}$ dimensions, with a vertical notch in the middle of their length of $2.5 \mathrm{~mm}$ height (Figure 1(c)) and Izod impact tests were performed using an impact loading apparatus (Tinius Olsen, Inc., Horsham, USA). Impact strength was calculated in $\mathrm{J} / \mathrm{m}$.

\section{Dynamic thermomechanical analysis (DMA)}

The dynamic thermomechanical properties of the nanocomposites were measured with a dynamic mechanical analyzer (Perkin Elmer Instruments, Waltham Massachusetts, USA). Testing was performed on rectangular bars $(30 \times 10 \times 3 \mathrm{~mm})$ whose exact dimensions were measured prior to testing. The bending method was used at a frequency of $1 \mathrm{~Hz}$, heating rate $3^{\circ} \mathrm{C} / \mathrm{min}$, strain level of $0.04 \%$ and temperature range 25 to $200^{\circ} \mathrm{C}$. Storage modulus (E'), loss modulus ( $\mathrm{E}^{\prime \prime}$ ), and tangent delta $(\tan \delta)$ were plotted against temperature.

\section{Scanning electron microscopy (SEM)}

In order to observe the fractured surfaces, one randomly selected specimen from the groups PMMA-ND $0.10 \%$, $0.38 \%$ and $0.83 \%$ was mounted on aluminium stubs, stabilized with silver paint and carbon-coated. Observations were performed and photomicrographs were taken from the fractured area with a scanning electron microscope (J.S.M. 840A, JEOL, Tokyo, Japan).

\section{Transmission electron microscopy (TEM)}

Transmission electron microscopy (TEM) observations (120 CX, JEOL, Tokyo, Japan) were performed on ultra thin film samples of the various nanocomposites, prepared by an ultra-microtome. These thin films were deposited on copper grids.

\section{Statistical methods}

Pilot studies with 4 specimens from each group and each variable (F.T. and I.S.) were conducted and power analysis was performed with $\mathrm{G} *$ Power 3.0.10 statistical power analysis software ${ }^{32)}$. The power analysis was based on the overall hypothesis concerning the equality between the mean values of the five groups which would be tested by One Way Anova, with $\alpha=0.05$ and power $\gamma=0.8$. The optimal sample size for F.T. was $n=6$ and $n=8$ for I.S. for each group. The assumption of normality for each group was tested by Shappiro-Wilk test. The assumption of homogeneity of variances concerning the between subjects factor was done by Levene's test of equality of error variances. The overall hypothesis concerning differences among the test groups' mean values of fracture toughness and impact strength was tested by One Way Anova, while multiple pair-wise comparisons were made with Bonferroni post hoc tests (statistical significance was set at $p<0.05$ ).

\section{RESULTS}

Fracture toughness (Three-point bending test) and impact strength (Izod impact test)

In the force-extension graphs presented in Figure 2(a) an abrupt and linear inclination of the line after reaching the maximum force is apparent and indicates the extension at which the fracture took place. All stressstrain curves show a linear increase until break. Mean values of fracture toughness $\left(\mathrm{K}_{\mathrm{Ic}}\right)$ are presented in Fig. $2(b)$. There was an increase of $K_{\text {Ic }}$ as the ND percentage increased up to $0.38 \% \mathrm{wt}$, although the increase was statistically significant only for the PMMA-ND $0.10 \%$ composite specimens compared to the control group. Higher ND amount seems to induce a decrease in $\mathrm{K}_{\mathrm{Ic}}$ mean values, in relation to control PMMA specimens. One Way Anova of $K_{I c}$ revealed statistical significant differences $(p<0.001)$ between control PMMA and PMMA-ND composite specimens (Table 1). Bonferroni multiple comparisons tests revealed that the increase in $\mathrm{K}_{\mathrm{Ic}}$ was statistically significant for the PMMA-ND $0.10 \%$ composite compared to both control PMMA and PMMA-ND composites with $0.50 \%$ and $0.83 \%$ ND powder (Table 2). From stress-strain curves Young's Modulus was calculated and plotted against ND content in Figure 2(c). As can be seen, increasing the content of ND in the PMMA-ND nanocomposites, the Young's Modulus increases linearly.

Control PMMA resin presented the lowest impact strength, while the highest impact strength values were recorded for the PMMA-ND 0.10\% composite, following by the PMMA-ND $0.83 \%$ composite, as shown in Figure 3. One Way Anova analysis of impact strength revealed statistical significant differences between groups (Table 3). In particular, PMMA-ND 0.10\% composites presented statistically significant higher strength compared to control PMMA resin $(p=0.013)$, which also presented statistically significant lower strength compared to the PMMA-ND $0.83 \%$ composites $(p=0.025)$ (Table 4).

\section{$D M A$}

Storage modulus ( $\left.\mathrm{E}^{\prime}\right)$, loss modulus $\left(\mathrm{E}^{\prime \prime}\right)$ and $\tan \delta$ of control PMMA and all the PMMA-ND nanocomposite specimens are presented in Figure 4. All tested specimens sharply dropped their elastic modulus when the temperature was raised from 20 to $140^{\circ} \mathrm{C}$. DMA analysis showed that $\mathrm{E}^{\prime}$ increased with $\mathrm{ND}$ content, indicating that the materials became stiffer due to the reinforcement effect of nanodiamonds (Figure 4(a)). When the temperature was raised, the loss modulus $\mathrm{E}^{\prime \prime}$ of all the materials tested increased until it reached its maximum in the glass transition region (Figure 4(b)). Thereafter, it 


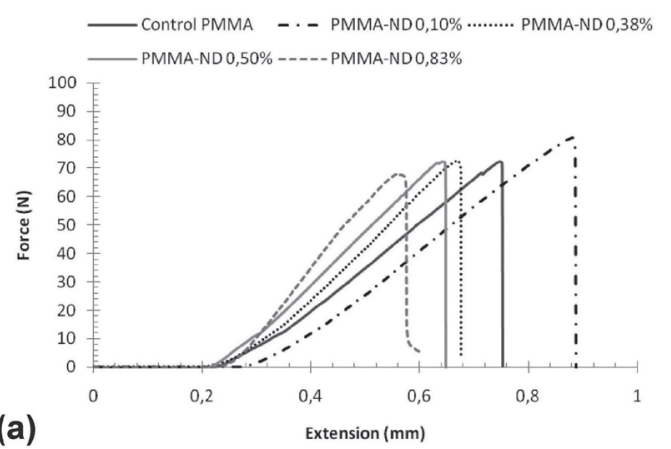

Mean values of fracture toughness (MPa.m ${ }^{1 / 2}$ )
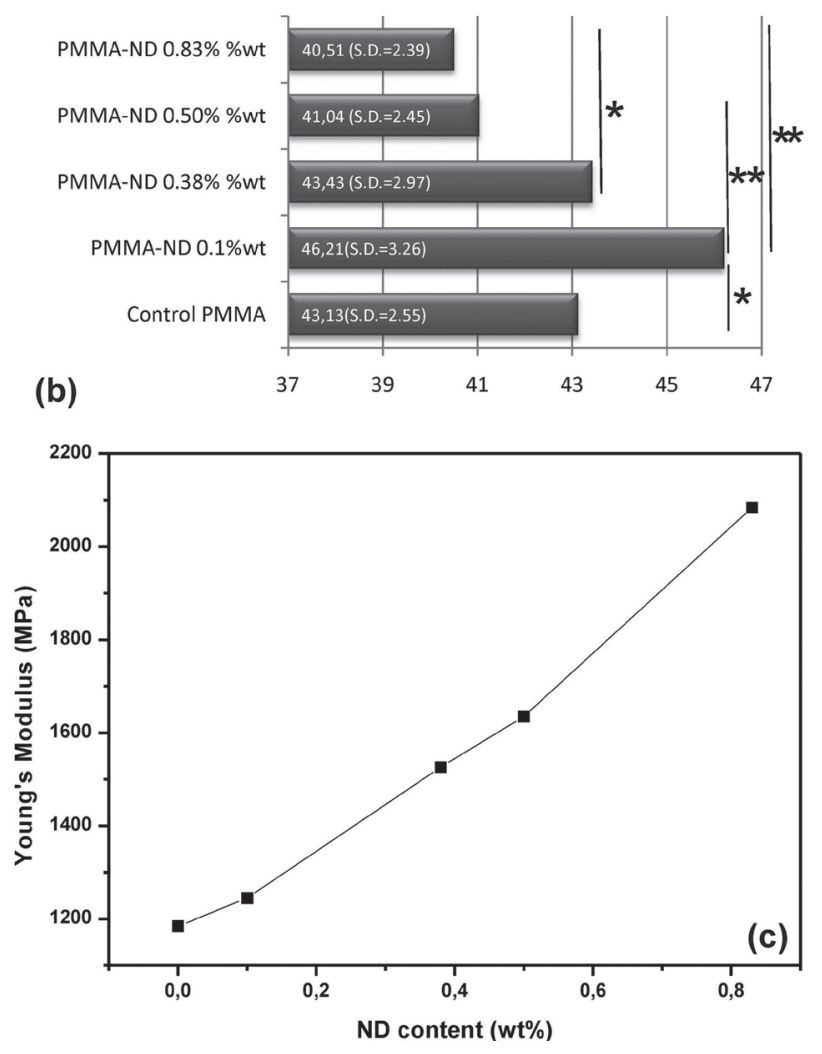

Fig. 2 (a) Representative stress-strain diagram as produced from fracture toughness values, (b) Mean values and Standard Deviation of $\mathrm{K}_{\mathrm{Ic}}$ of control PMMA and PMMA-ND composite specimens: $\quad * p<0.05, \quad * * p<0.001, \quad$ (c) Young's Modulus of PMMA-ND composites versus ND content (wt\%).

continuously decreased as the temperature rose. Tan $\delta$ is also recorded in the form of a peak the maximum of which is attributed to the glass transition temperature $\left(\mathrm{T}_{\mathrm{g}}\right.$ ) of the resin. Control PMMA presented $\mathrm{T}_{\mathrm{g}}$ at $96^{\circ} \mathrm{C}$, while the $\mathrm{T}_{\mathrm{g}}$ of nanocomposites increased significantly (mean difference from control $19-21^{\circ} \mathrm{C}$ ) as presented in Figure 4(c). Furthermore, this increase is directly

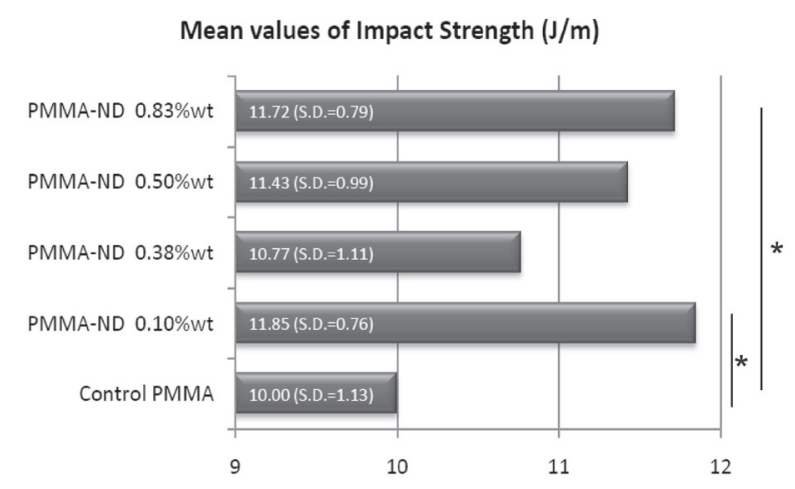

Fig. 3 Mean values and Standard Deviation of Impact Load strength of control PMMA and PMMA-ND composite specimens: ${ }^{*} p<0.05$.

depended from the nanodiamonds content.

\section{SEM}

The fracture started at the highest portion of the notch and propagated towards the point of the applied load. Most specimens did not separate totally after break detection, however almost all of the specimens of the PMMA-ND $0.83 \%$ group were split in two parts during the 3-point bending test. In the SEM microphotographs in Figures 5 (a), (c) and (e), the presence of voids due to air entrapment during mixing and mold filling can be observed in all specimens (control PMMA and PMMA-ND composite specimens). An area of $500 \mu \mathrm{m}$ to $1 \mathrm{~mm}$ with flake-like morphology is observed close to the fractured area in all specimens. A sharp crack surface with no noticeable plastic deformation is observed for the PMMA In figure 5b. A multi-stepped fracture pattern with characteristic striations parallel to the local crack propagation direction, propagating deep inside the matrix of the specimens of the PMMA-ND $0.38 \%$ is clearly seen in the respective microphotographs (Figures 5 (c) and (d)). Many major and even more minor cracks are present on the fractured area of the PMMA-ND $0.83 \%$ group (Figure 5(e), (f)).

TEM

A uniform distribution of ND particles is observed (Figure 6(a)) while a few ND particles are in contact with each other to form aggregates (black arrows). In some areas the aggregates have coalesced to form larger agglomerates (white arrows). At higher magnifications (Figure 6(b)), a characteristic mosaic structure is observed, where primary polyhedral ND particles of 4-5 $\mathrm{nm}$ seem to be loosely interconnected inside the agglomerates (Figure 6(c)).

\section{DISCUSSION}

The fracture toughness under load is an important 
Table 1 One way analysis of variance of fracture toughness

\begin{tabular}{|c|c|c|c|c|c|}
\hline & Sum of Squares & $\mathrm{df}$ & Mean Square & $\mathrm{F}$ & Sig. \\
\hline Between Groups & 330.673 & 4 & 82.668 & 11.191 & $<0.001$ \\
\hline Within Groups & 561.438 & 76 & 7.387 & & \\
\hline Total & 892.111 & 80 & & & \\
\hline
\end{tabular}

Table 2 Bonferroni post hoc multiple comparisons tests of fracture toughness

\begin{tabular}{|c|c|c|c|c|c|c|}
\hline \multirow[t]{2}{*}{ Specimens groups } & & \multirow{2}{*}{$\begin{array}{l}\text { Mean } \\
\text { difference }\end{array}$} & \multirow[t]{2}{*}{ Std. Error } & \multirow[t]{2}{*}{ Sig. } & \multicolumn{2}{|c|}{ 95\% Confidence interval } \\
\hline & & & & & Lower bound & Upper bound \\
\hline \multirow[t]{4}{*}{ Control PMMA } & PMMA-ND 0.10\% & -3.0742 & 0.99246 & $0.027(*)$ & -5.9437 & -0.2047 \\
\hline & PMMA-ND 0.38\% & -0.29622 & 0.99246 & 1 & -3.1657 & 2.5733 \\
\hline & PMMA-ND $0.50 \%$ & 2.09187 & 0.95021 & 0.307 & -0.6555 & 4.8392 \\
\hline & PMMA-ND 0.83\% & 2.61695 & 0.95021 & 0.074 & -0.1304 & 5.3643 \\
\hline \multirow[t]{3}{*}{ PMMA-ND 0.10\% } & PMMA-ND 0.38\% & 2.77798 & 0.99246 & 0.065 & -0.0915 & 5.6475 \\
\hline & PMMA-ND 0.50\% & 5.16607 & 0.95021 & $<0.001$ & 2.4187 & 7.9134 \\
\hline & PMMA-ND $0.83 \%$ & 5.69116 & 0.95021 & $<0.001$ & 2.9438 & 8.4385 \\
\hline \multirow[t]{2}{*}{ PMMA-ND 0.38\% } & PMMA-ND 0.50\% & 2.38809 & 0.95021 & 0.141 & -0.3592 & 5.1354 \\
\hline & PMMA-ND $0.83 \%$ & 2.91317 & 0.95021 & $\left.0.030{ }^{*}\right)$ & 0.1658 & 5.6605 \\
\hline PMMA-ND $0.50 \%$ & PMMA-ND 0.83\% & 0.52509 & 0.90599 & 1 & -2.0944 & 3.1446 \\
\hline
\end{tabular}

* The mean difference is significant at the 0.05 level

Table 3 One way analysis of variance of impact load strength

\begin{tabular}{lccccc}
\hline & Sum of Squares & df & Mean Square & F & Sig. \\
\hline Between Groups & 18.926 & 4 & 4.732 & 5.071 & 0.002 \\
Within Groups & 32.658 & 35 & 0.933 & & \\
Total & 51.584 & 39 & & \\
\hline
\end{tabular}

Table 4 Bonferroni post hoc multiple comparisons tests of impact load strength

\begin{tabular}{|c|c|c|c|c|c|c|}
\hline \multirow[t]{2}{*}{ Specimens groups } & & \multirow{2}{*}{$\begin{array}{l}\text { Mean } \\
\text { difference }\end{array}$} & \multirow[t]{2}{*}{ Std. Error } & \multirow[t]{2}{*}{ Sig. } & \multicolumn{2}{|c|}{ 95\% Confidence interval } \\
\hline & & & & & Lower bound & Upper bound \\
\hline \multirow[t]{4}{*}{ Control PMMA } & PMMA-ND $0.10 \%$ & -1.8525 & 0.4829783 & $0.013(*)$ & -3.422429 & -0.282571 \\
\hline & PMMA-ND 0.38\% & -0.76625 & 0.4829783 & 0.645 & -2.336179 & 0.803679 \\
\hline & PMMA-ND 0.50\% & -1.43125 & 0.4829783 & 0.09 & 3.001179 & 0.138679 \\
\hline & PMMA-ND 0.83\% & -1.71875 & 0.4829783 & $0.025\left(^{*}\right)$ & 3.288679 & -0.148821 \\
\hline \multirow[t]{3}{*}{ PMMA-ND 0.10\% } & PMMA-ND 0.38\% & 1.08625 & 0.4829783 & 0.302 & -0.483679 & 2.656179 \\
\hline & PMMA-ND 0.50\% & 0.42125 & 0.4829783 & 0.942 & -1.148679 & 1.991179 \\
\hline & PMMA-ND $0.83 \%$ & 0.13375 & 0.4829783 & 0.999 & -1.436179 & 1.703679 \\
\hline \multirow[t]{2}{*}{ PMMA-ND $0.38 \%$} & PMMA-ND $0.50 \%$ & -0.665 & 0.4829783 & 0.755 & -2.234929 & 0.904929 \\
\hline & PMMA-ND $0.83 \%$ & -0.9525 & 0.4829783 & 0.435 & -2.522429 & 0.617429 \\
\hline PMMA-ND $0.50 \%$ & PMMA-ND $0.83 \%$ & -0.2875 & 0.4829783 & 0.985 & -1.857429 & 1.282429 \\
\hline
\end{tabular}

* The mean difference is significant at the 0.05 level 
mechanical property of dental polymers as it provides information concerning crack propagation. Fracture toughness is described by the critical stress intensity factor $\mathrm{K}_{\mathrm{Ic}}$, which indicates the critical stress limit at the
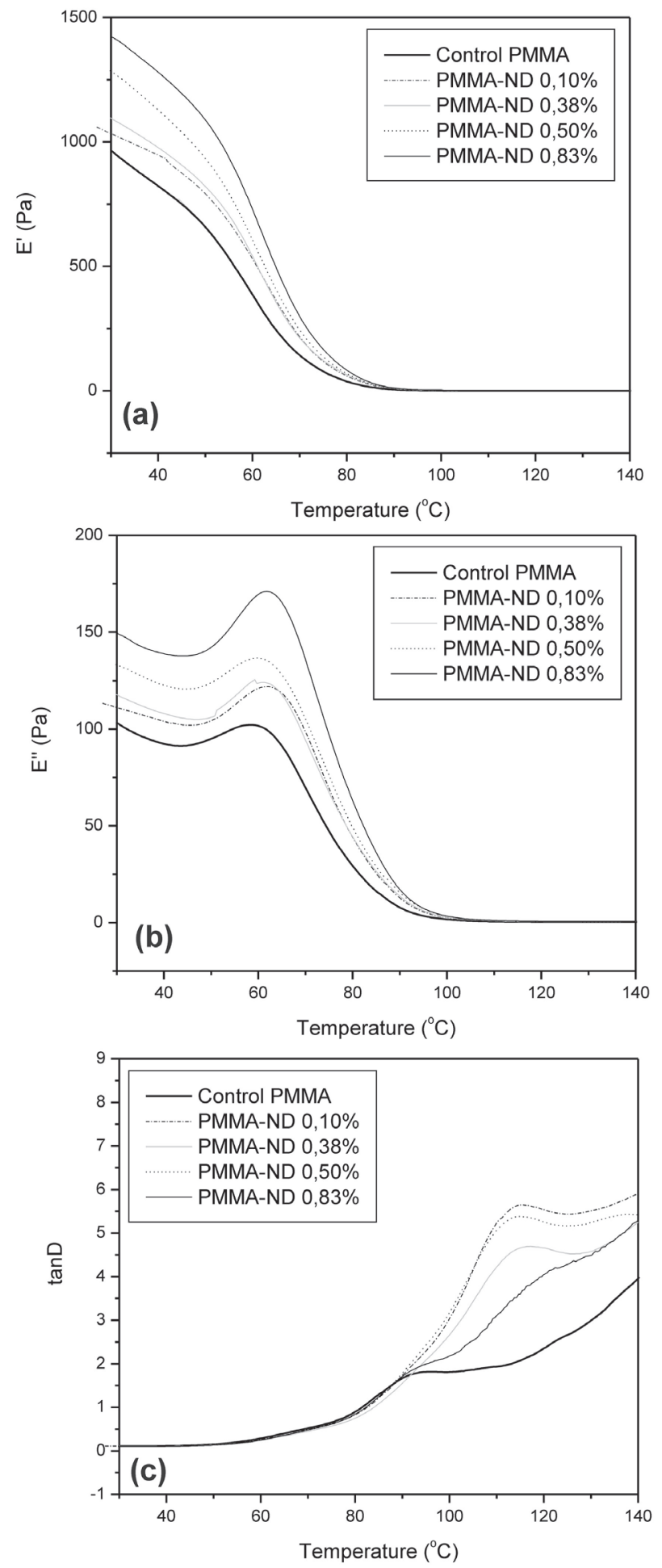

Fig. 4 Storage modulus (E') (a), Loss Modulus (E'') (b) and $\tan \delta$ (c) of control PMMA and PMMA-ND composites. mechanical failure (crack propagation) of the specimen ${ }^{33)}$. The impact resistance represents the total energy absorbed by a material before it fractures, when struck by a sudden blow from an impact instrument with a weighted pendulum ${ }^{34)}$. In clinical practice interim restorations often fail suddenly especially after heavy biting on a hard piece of food, most probably due to the propagation of a pre-existing crack. Thus it is important for any material for that type of restorations to attain high values of both fracture toughness and impact strength, especially if a long-term clinical performance is anticipated.

Various procedures for reinforcing PMMA resins have been suggested ${ }^{5-10}$ but, some have demonstrated limited success ${ }^{10,35)}$. In the present study increase of the fracture toughness was recorded only in the lower concentrations of ND nano-particles (0.10 and $0.38 \mathrm{wt} \%$ ), although it was statistically significant only for the PMMA-ND 0.10\% group. Due to their surface functional groups, the individual ND particles structurally selforganize into aggregates of 20-30 nm size, which in turn form larger agglomerates ranging from hundreds of nanometers to micrometer sizes that are kept together through weak hydrogen bonds which are very difficult to break down during nanocomposites formation. A compromise of the mechanical properties of ND-polymer composites has been attributed to the poor dispersion due to agglomeration/reagglomeration of the nanodiamonds within the polymer matrix ${ }^{16,36)}$. As shown by TEM a good dispersion of ND particles has been achieved in the PMMA-ND 0.1\% composites, although the simultaneous existence of small areas of aggregated particles was evidenced. The relative homogenous dispersion of the particles can explain the increase of the fracture toughness and the impact strength of the respective composites. Higher concentrations of ND lead to agglomeration ${ }^{37)}$, so by using lower ND additions, a combination of a good dispersion with a probable moderate to enhanced improvement of the mechanical properties can be achieved.

To gain more insight into the toughening mechanism, the fractured surfaces of PMMA-ND composites with different ND contents were examined by SEM. As shown in Fig. 5(a) the crack surface in PMMA is sharp with no noticeable plastic deformation. When nanodiamonds are added, the micrographs changed slightly as shown in Figs. 5(d) and 5(f). In the crack propagation zone of nanocomposites, regular striations associated with highly plastically deformed fibers of PMMA matrix are seen parallel to the direction of crack propagation (Fig. $5(\mathrm{c})$ ), indicating that the matrix undergoes higher plastic deformation ${ }^{38}$. It seems that the addition of ND results in more energy dissipation, thus improving the toughness. Since ND are fine dispersed in PMMA matrix, they act as effective stiffeners. This could be attributed to the increased interface interaction between PMMA and $\mathrm{ND}$, since they have a lot of reactive groups $\left(-\mathrm{NH}_{2}\right.$, $-\mathrm{OH}$, etc.) which could form hydrogen bonds with carbonyl groups of PMMA ${ }^{39,40)}$. Thus it can be said that the propagation crack proceeds along this interface. 


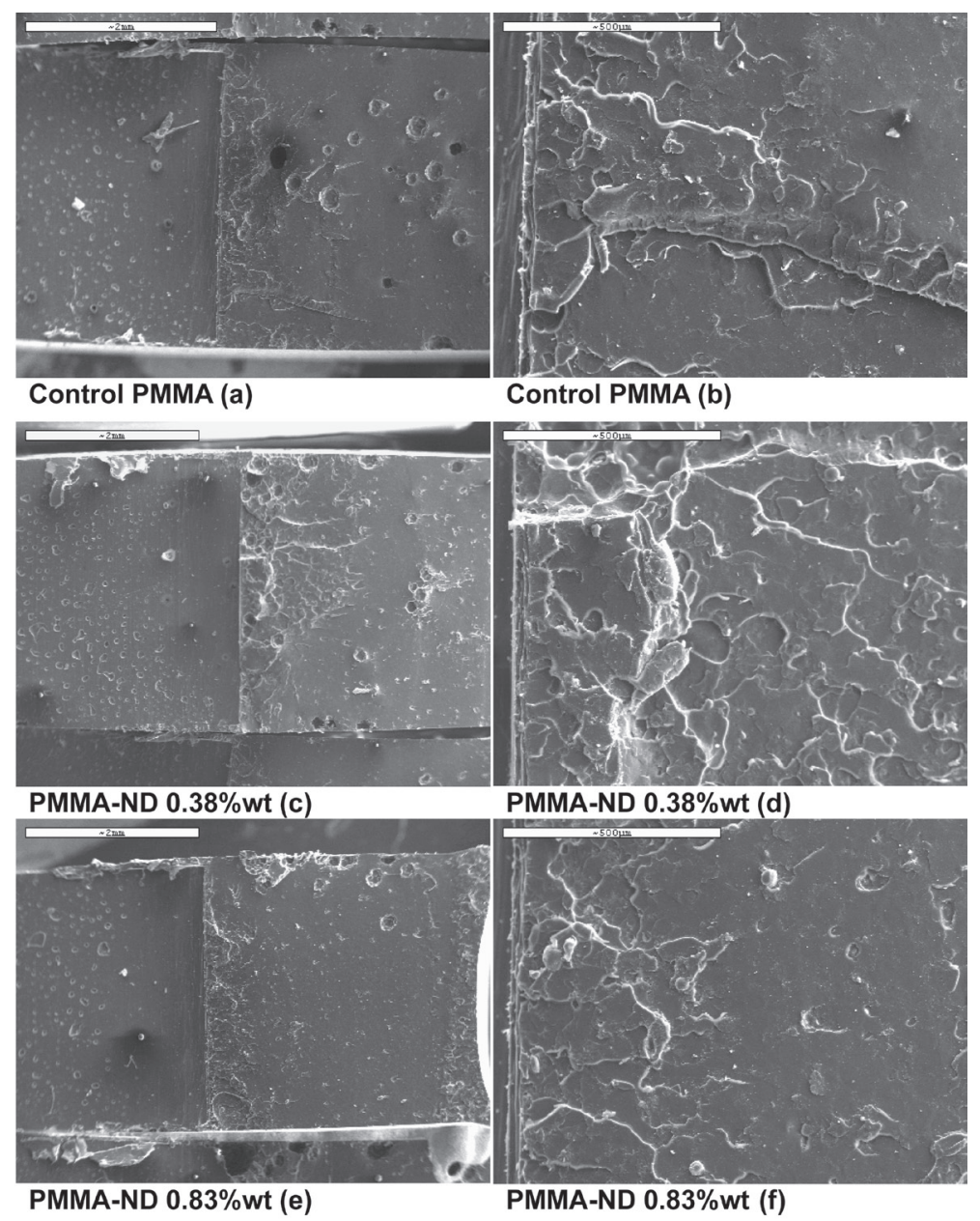

Fig. 5 SEM microphotographs of representative fractured specimens.

However, this fracture toughness is not continuous and as can be seen from Figure 2(b), at higher nanodiamonds content than $0.50 \%$ wt the fracture toughness decreases. As can be seen from Figure 5(d) the fracture surface at the nanocomposite containing $0.83 \%$ wt ND is similar to that of neat PMMA.

The results for impact strength were slightly different. As can be seen from Figure 3 significant increase of impact strength was recorded for all PMMA-ND composites compared to control, which means that the composites became able to withstand better a sudden and high load, for example during biting on a very hard material. Surprisingly, the increase in impact strength did not correlate well with the decrease in fracture toughness for PMMA-ND $0.50 \%$ and PMMA-ND $0.83 \%$ composites. A decrease in impact strength for these samples instead of an increase would be expected. This difference can be associated with internal cross-linking parameters that lead to the strengthening of the materials to impact load tests that are carried out at a very high speed ${ }^{41)}$. However a distinct straight correlation between the results of these techniques should not be performed because of the differences in (a) the notch acuity of the $\mathrm{K}_{\mathrm{Ic}}$ and I.S. specimens and the loading rates in the tests ${ }^{42)}$. This further impact strength increase for nanocomposites containing higher than $0.38 \%$ ND should be clearly attributed to the existence of nanodiamonds. In many polymers it was reported that nanoparticles can lead to toughening improvement due to the percolation effect and the critical interparticle distance of nanoparticles ${ }^{43)}$. According to $\mathrm{Wu}^{44)}$, this distance is close to the sum of diameters of two particles and when there is a sufficient interpenetration of the plastic zones formed around the particles, propagation of the microcrackings in the matrix does not occur but instead is drastically inhibited. This may result in a substantial increase in impact strength at higher nanodiamonds loading. Furthermore, an additional explanation for this impact toughening is that the agglomerates formed into higher ND content were broken down into smaller sizes as a result of energy absorption. Kim et al. ${ }^{45)}$ proposed such a mechanism comprising a multiple debonding process for silica aggregates in polyethylene/ $\mathrm{SiO}_{2}$ nanocomposites. In this mechanism, stress concentration takes place in aggregates comprised of the soft particles during the 

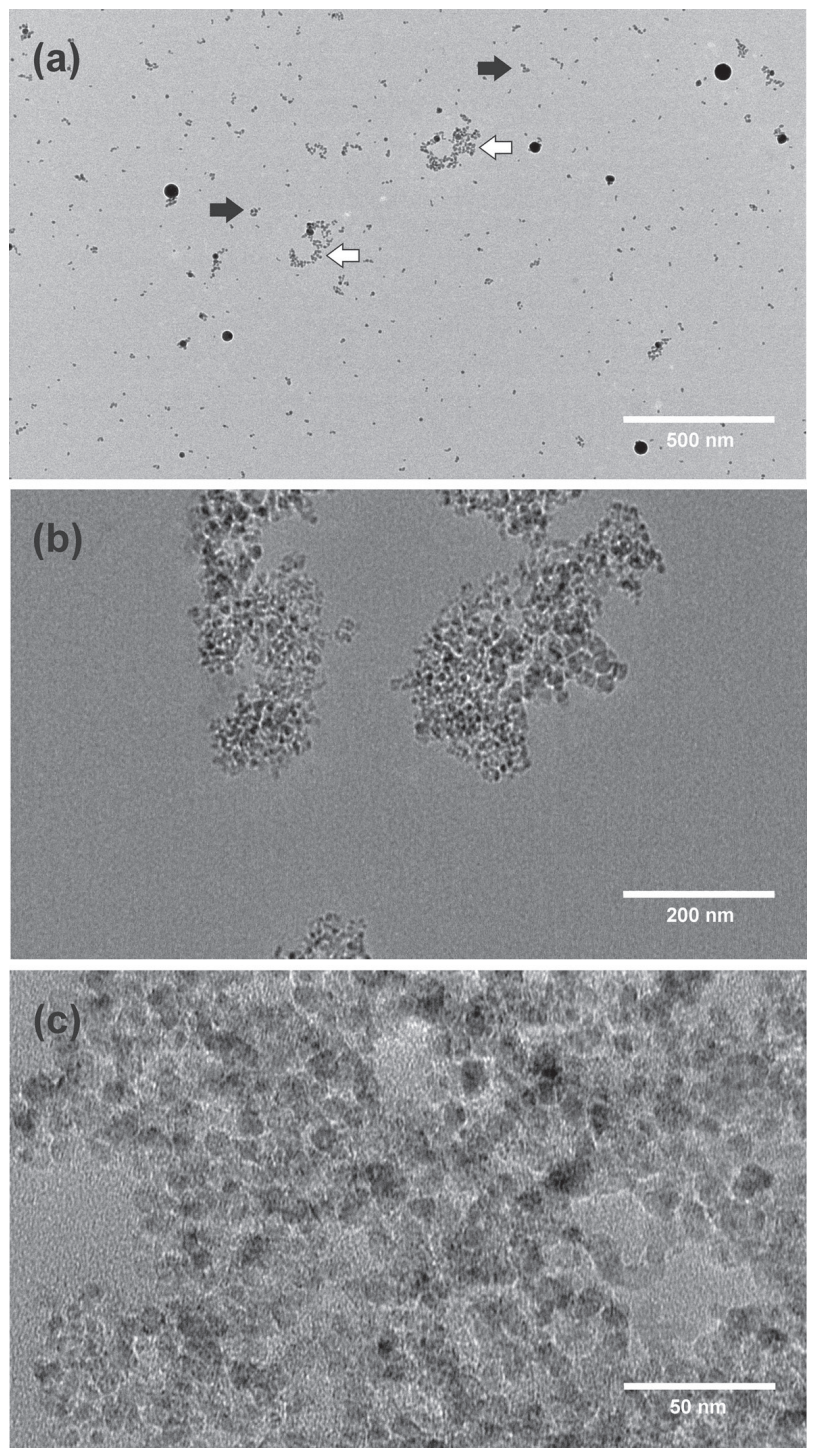

Fig. 6 TEM images from a PMMA-ND 0.10 \%wt composite. Black arrows: ND particles forming aggregates. White arrows: ND particles coalesced to agglomerates.

deformation process. Because of the small interparticle distance, the shear flow process and fibrillation are activated inside the agglomerates, and the matrix between the aggregates deforms plastically, increasing toughness. Increasing the ND amount, the formed agglomerates are also increased, which can cause a further enhancement of impact toughening.

Control PMMA and PMMA-ND composites presented similar curves under stress intensity (Figure 2(a)). All stress-strain curves showed a linear increase until break in accordance with the theory of linear elastic fracture mechanics ${ }^{46)}$ for brittle fracture, indicating the brittle nature of the fracture mode. In brittle fracture the material fails without plastic deformation as a result of the very rapid propagation of unstable cracks. Once these unstable cracks are initiated, they will continue to propagate spontaneously without an increase in the applied stress. This finding is further verified by the SEM observations where the brittle fracture is characterized by a disorganized surface with multistepped morphology. Similar polymer fracture characteristics have been addressed in other studies too, suggesting that polymers exhibit primarily brittle fractures ${ }^{47,48)}$. However, despite their brittle nature, all nanocomposites presented very high Young's Modulus (Fig. 2(c)). As can be seen, neat PMMA has a value of 1,184 MPa while increasing the content of ND Young's Modulus increases progressively and reaches its highest value $(2,084 \mathrm{MPa})$ at $\mathrm{ND}$ content $0.83 \%$ wt. This is an indication that nanocomposites are stiffer than neat PMMA due to the existence of ND. It is remarkable that very small amounts of ND are sufficient to gain a very high increase of Young's Modulus. This is due to the rigidity of $\mathrm{ND}$ as neat materials since in most cases nanoparticles have Young's Modulus higher than 1 TPa.

In vitro static load tests differ from the dynamic intraoral conditions. The masticatory system performs complex rhythmic movements with mean chewing frequency of $\sim 1 \mathrm{~Hz}^{49-51)}$. Consequently, dynamic tests such as dynamic mechanical analysis (DMA) are particularly well suited for visco-elastic materials, since they can determine both the elastic and viscous responses of a sample in one experiment with frequency of $\sim 1$ $\mathrm{Hz}^{52,53)}$. The storage modulus ( $\left.\mathrm{E}^{\prime}\right)$ is equivalent to Young's modulus of elasticity, which is an indication of the material stiffness or rigidity. It is also a measure of the amount of energy returned to the system elastically after a strain is imparted. The loss modulus ( $\mathrm{E}^{\prime \prime}$ ) is an indication of energy absorbed/lost by the materials which is not returned elastically ${ }^{54)}$. Instead, this energy is used to increase segmental molecular vibration or to translate chain positions. The dynamic modulus of a composite depends on many factors such as the filler fraction and distribution, the nature of the matrix, and the fillermatrix interactions ${ }^{54)}$. In the present study the $\mathrm{E}^{\prime}$ around $37^{\circ} \mathrm{C}$ increased almost linearly with the ND content in the composites, indicating an additional elastic response compared to control PMMA, which is in agreement with Young's Modulus increase. An elastic behavior is to a certain extent desirable as the elastically deformed material will absorb a greater amount of energy before its fracture or the transmission of the occlusal forces to the underlying dentine. From Figure 4(a) it can be seen that even at temperatures $60-70^{\circ} \mathrm{C}$ storage modulus of nanocomposites is higher than the corresponding of neat PMMA. This improvement is very important for the materials used for interim restorations and ND seem to improve the performance of PMMA resin.

One additional positive effect from nanodiamonds application in PMMA is the glass transition temperature increase. $\mathrm{T}_{\mathrm{g}}$ can be expressed as the primary peak in transition events observed in analyzing DMA plots by loss modulus values, by changes in the phase angle between the storage modulus and the loss modulus, or by the tan delta values ${ }^{55,56)}$. The value of $\mathrm{T}_{\mathrm{g}}$ can have great 
influence on the dimensional stability and internal stresses developed during the performance of the material at high temperature ${ }^{57}$. A high value of loss tangent is more effective for stress distribution in clinical situations ${ }^{58}$. In this study PMMA resin presented $\mathrm{T}_{\mathrm{g}}$ at $96^{\circ} \mathrm{C}$, while the $\mathrm{T}_{\mathrm{g}}$ of nanocomposites increased significantly (mean difference from control: $19-21^{\circ} \mathrm{C}$ ) at temperatures safely above those encountered in mouth (Figure 4(c)). Materials which are characterized as being rigid and having a high crosslink density also tend to have higher glass transition temperatures ${ }^{59,60)}$. In the case of nanocomposites, the $\mathrm{T}_{\mathrm{g}}$ of a polymeric matrix tends to increase with the addition of nanoparticles, due to the interactions between the polymer chains (carbonyl groups) and the nanoparticles (surface hydroxyl groups) and to the reduction of macromolecular chain mobility at the zone surrounding the nanoparticles ${ }^{61)}$. This transition zone exhibits higher modulus and $\mathrm{T}_{\mathrm{g}}$, both of which are gradually reduced with increasing distance from the filler surface. An increase in cross-linking has been reported to explain the increased polymer composite strength resulting from ND addition ${ }^{18}$.

Although it is claimed that a reinforcing effect can be anticipated by the use of nanodiamonds, the results of this in vitro study should be carefully considered, as significant variations are possible under intraoral conditions with saliva and its potential plasticizing effect on the materials. Furthermore a slight change in color which was more profound as the ND content increased above $0.38 \% \mathrm{wt}$ constitutes a restricting factor for the use of these composites in the esthetic area. Lower volume fractions of ND nanoparticles might have resulted in more optimum and/or homogenous dispersion in the polymer matrix, leading to even better static and dynamic mechanical properties, without compromising esthetics, which is important even if these restorations are only intended for a short period of function.

\section{CONCLUSIONS}

The reinforcement of the tested PMMA dental resin resulted in a statistically significant increase of its impact strength but its fracture toughness was significantly improved only at the lowest ND concentration. A remarkable increase of the $T_{g}$ was recorded in all PMMA-ND composite specimens. Under the limitations of this in vitro study it can be concluded that reinforcing PMMA with ND nanoparticles especially at low concentrations- may increase the overall performance of fixed interim prostheses.

\section{ACKNOWLEDGMENTS}

The authors wish to acknowledge the help of Dr. Vasilios Karagiannis, a mathematician employed in the Department of Operative Dentistry, Faculty of Dentistry, Aristotle University of Thessaloniki, Greece, for the statistical analysis of the data.

\section{REFERENCES}

1) Gratton DG, Aquilino SA. Interim restorations. Dent Clin North Am 2004; 48: 487-497.

2) Lang R, Rosentritt M, Behr M, Handel G. Fracture resistance of PMMA and resin matrix composite-based interim FPD materials. Int J Prosthodont 2003; 16: 381-384.

3) Motta AB, Pereira LC, da Cunha AR, Duda FP. The influence of the loading mode on the stress distribution on the connector region of metal-ceramic and all-ceramic fixed partial denture. Artif Organs 2008; 32: 283-291.

4) Manda M, Galanis C, Georgiopoulos V, Provatidis C, Koidis P. Effect of severely reduced bone support on the stress field developed within the connectors of three types of cross-arch fixed partial dentures. J Prosthet Dent 2009; 101: 54-65.

5) Vallittu PK. A Review of methods used to reinforce polymethyl methacrylate resin. J Prosthodont 1995; 4: 183-187.

6) Zuccari AG, Oshida Y, Moore BK. Reinforcement of acrylic resins for provisional fixed restorations, Part I: Mechanical properties. Biomed Mater Eng 1997; 7: 327-343.

7) Vallittu PK. Flexural properties of acrylic resin polymers reinforced with unidirectional and woven glass fibers. J Prosthet Dent 1999; 81: 318-326.

8) Panyayong W, Oshida Y, Andres CJ, Barco TM, Brown DT, Hovijitra S. Reinforcement of acrylic resins for provisional fixed restorations. Part III: effects of addition of titania and zirconia mixtures on some mechanical and physical properties. Biomed Mater Eng 2002; 12: 353-366.

9) Kim SH, Watts DC. Effect of glass-fiber reinforcement and water storage on fracture toughness $\left(\mathrm{K}_{\mathrm{IC}}\right)$ of polymer-based provisional crown and FPD materials. Int J Prosthodont 2004; 17: 318-322.

10) Geerts G, Overturf J-H, Oberholzer TG. The effect of different reinforcements on the fracture toughness of materials for interim restorations. J Prosthet Dent 2008; 99: 461-467.

11) Zheng $Y$, Zheng $Y$, Ning R. Effects of nanoparticles $\mathrm{SiO}_{2}$ on the performance of nanocomposites. Materials Letters 2003; 57: 2940-2944.

12) Raty JY, Galli G. Optical properties and structure of nanodiamonds. J Electroanalyt Chem 2005; 584: 9-12.

13) Dolmatov VY. Polymer-diamond composites based on detonation nanodiamonds. Part 1. J Superhard Mater 2007; 29: 1-11.

14) Shenderova O, McGuire G. In: Gogotsi Y, editor. Carbon nanomaterials. Philadelphia: CRC Press Taylor \& Francis Group; 2006. p.175-210.

15) $\mathrm{Hu} \mathrm{Y}$, Shenderova OA, Hu Z, Padgett CW, Brenner DW. Carbon nanostructures for advanced composites. Report Progr Phys 2006; 69: 1847-1895.

16) Karbushev V V, Konstantinov II, Parsamyan IL, Kulichikhin VG, Popov VA, George TF. Preparation of polymernanodiamond composites with improved properties. Adv Mater Res 2009; 59: 275-278.

17) Stavrev S. US Patent 5.353.708, 1994.

18) Dolmatov VY. Detonation synthesis ultradispersed diamonds: properties and applications. Russ Chem Rev 2001; 70: 607-626.

19) Butenko YV, Kuznetsov VL, Paukshtis EA, Stadnichenko AI, Mazov IN, Moseenkov SI, Boronin AI, Kosheev SV. The thermal stability of nanodiamond surface groups and onset of nanodiamond graphitization. Fuller Nanotub Car N 2006; 14: 557-564.

20) Grichko V, Shenderova O. In: Shenderova OA, Gruen DM, editors. Ultrananocrystalline diamond: Synthesis, properties, and applications Norwich: William Andrew; 2006. p. 531-536.

21) Khaled SM, Sui R, Charpentier PA, Rizkalla AS. Synthesis of $\mathrm{TiO}_{2}$-PMMA nanocomposite: Using Methacrylic Acid as a coupling agent. Langmuir 2007; 23: 3988-3995.

22) Dolmatov VY, Voznyakovskii AP, Veretennikova MV. 
Modification of polymers using detonation-synthesized ultradispersed diamonds (nanodiamonds). Superhard Mater 2001; 23: 75-78.

23) Voznyakovskiy AP, Dolmatov VY, Veretennikova MV. Nanocomposites based on polyblock polysiloxane copolymers and nanodiamonds. Distribution topology features and properties. Superhard Mater 2003; 25: 21-30.

24) Sirotinkin NV, Voznyakovskii AP, Ershova AN. Model of formation of three-dimensional polyurethane films modified by detonation nanodiamonds. Phy Solid State 2004; 46: 746-747.

25) Shenderova O, Tyler T, Cunningham G, Ray M, Walsh J, Casulli M, Hens S, McGuire G, Kuznetsov V, Lipa S. Nanodiamond and onion-like carbon polymer nanocomposites. Diamond Relat Mater 2007; 16: 1213-1217.

26) Dolmatov VY. Polymer-diamond composites based on detonation nanodiamonds. Part 2. J Superhard Mater 2007; 29: 65-75.

27) d'Almeida JRM, Monteiro SN, Menezes GW, Rodriguez RJS. Diamond-epoxy composites. J Reinforced Plastics Composites 2007; 26; 321-330.

28) British standard BS EN ISO 12737:2005: Metallic materials -Determination of plane-strain fracture toughness, Aug. 2005.

29) Gegauff AG, Pryor HG. Fracture toughness of provisional resins for fixed prosthodontics. J Prosthet Dent 1987; 58: $23-29$.

30) Ireland MF, Dixon DL, Breeding LC, Ramp MH. In vitro mechanical property comparison of four resins used for fabrication of provisional fixed restorations. J Prosthet Dent 1998; 80: 158-162.

31) ASTM D256 - 06ae1 Standard Test Methods for Determining the Izod Pendulum Impact Resistance of Plastics.

32) Faul F, Erdfelder E, Lang A-G, Buchner A. G*Power 3: A flexible statistical power analysis program for the social, behavioral, and biomedical sciences. Behav Res Meth 2007; 39: $175-191$.

33) Lloyd CH. The fracture toughness of dental composites. II. The environmental and temperature dependence of the stress intensification factor $\left(\mathrm{K}_{\mathrm{IC}}\right)$. J Oral Rehabil 1982; 9: 133-138.

34) Craig R, Powers JM. In: Craig R, Powers JM, editors. Restorative dental materials. 11th ed. St. Louis: Mosby Inc; 2002. p. 640-645.

35) Vallittu PK, Narva K. Impact strength of a modified continuous glass fiber--poly(methyl methacrylate). Int $\mathrm{J}$ Prosthodont 1997; 10: 142-148.

36) Behler KD, Stravato A, Mochalin V, Korneva G, Yushin G, Gogotsi Y. Nanodiamond-polymer composite fibers and coatings. ACS Nano 2009; 3: 363-369.

37) Maitra K, Prasad E, Ramamurty U, Rao CNR. Mechanical properties of nanodiamond-reinforced polymer-matrix composites. Solid State Commun 2009; 149: 1693-1697.

38) Pons A, Karma A. Helical crack-front instability in mixed-mode fracture. Nature 2010; 464: 85-89.

39) He J, Zhao N, Shi C, Du X, Li J, Nash P. Reinforcing copper matrix composites through molecular-level mixing of functionalized nanodiamond by co-deposition route. Mater Sci Eng A 2008; 490: 293-299.

40) Osswald S, Yushin G, Mochalin V, Kucheyev SO, Gogotsi Y. Control of sp2/sp3 carbon ratio and surface chemistry of nanodiamond powders by selective oxidation in air. J Am Chem Soc 2006;128: 11635-11642.

41) Price CA. The Effect of cross-linking agents on the impact resistance of a linear poly(methyl methacrylate) denture-base polymer. J Dent Res 1986; 65: 987-992.

42) Lewis G, Mladsi S. Correlation between impact strength and fracture toughness of PMMA-based bone cements. Biomaterials 2000; 21: 775-781.

43) Bikiaris D, Papageorgiou G, Pavlidou E, Vouroutzis N, Palatzoglou P, Karayannidis G. Preparation by melt mixing and characterization of isostatic polypropylene/ $\mathrm{SiO}_{2}$ nanocomposites containing untreated and surface-treated nanoparticles. J Appl Polym Sci 2006; 100: 2684-2696.

44) $\mathrm{Wu}$ S. Phase structure and adhesion in polymer blends: A criterion for rubber toughening. Polymer 1985; 26: 1855-1863.

45) Kim GM, Michler GH. Micromechanical deformation processes in toughened and particle filled semicrystalline polymers. Part 2: Model representation for micromechanical deformation processes. Polymer 1998; 39: 5699-5703.

46) Hargreaves AS. The effect of the environment on the crack initiation toughness of dental poly(methyl methacrylate). J Biomed Mater Res 1981; 15: 757-768.

47) Merrett K, Cornelius RM, McClung WG, Unsworth LD, Sheardown H. Surface analysis methods for characterizing polymeric biomaterials. J Biomater Sci Polym Ed 2002; 13: 593-621.

48) Callister WD Jr. In: Callister WD editor. Materials science and engineering: an introduction. 7th ed. John Wiley \& Sons; 2006. p. 232-234, 524-533.

49) Lavigne GJ, Rompre PH, Poirier G, Huard H, Kato T, Montplaisir JY. Rhythmic masticatory muscle activity during sleep in humans. J Dent Res 2001; 80: 443-448.

50) Lund JP. Mastication and its control by the brain stem. Crit Rev Oral Biol Med 1991; 2: 33-64.

51) Farella M, Palla S, Gallo LM. Time-frequency analysis of rhythmic masticatory muscle activity. Muscle Nerve 2009; 39: 828-836.

52) Sideridou I, Karabela M, Vouvoudi E. Dynamic thermomechanical properties and sorption characteristics of two commercial light cured dental resin composites. Dent Mater 2008; 24: 737-743.

53) Mesquita R, Axmann D, Geis-Gerstorfer J. Dynamic viscoelastic properties of dental composite resins. Dent Mater 2006; 22 : 258-267.

54) Nair KCM, Thomas S, Groeninckx G. Thermal and dynamic mechanical analysis of polystyrene composites reinforced with short sisal fibres. Comp Sci Technol 2001; 61: 2519-2529.

55) Chartoff RP, Weissman PT, Sircar AK. The application of dynamic mechanical methods to $\mathrm{Tg}$ determination in polymers: an overview. In: RJ Seyler, editor; Assignment of the glass transition, ASTM STP 1249. American Society for testing and materials, Philadelphia: 1994. p. 88-107.

56) Øysæd H. Dynamic mechanical properties of multiphase acrylic systems. J Biomed Mater Res 1990; 42: 1037-1048.

57) Muhtaroğulları IY, Doğan A, Muhtaroğulları M, Usanmaz A. Thermal and dynamic mechanical properties of microwave and heat cured poly(methylmethacrylate) used as dental base material. J Appl Poly Sci 1999; 74: 2971-2978.

58) Tanimoto Y, Nishiwaki T, Nemoto K. Dynamic viscoelastic behavior of dental composites measured by Split Hopkinson pressure bar. Dent Mater J 2006; 25: 234-240.

59) Wandlandt WW. Thermal analysis. 3rd ed. Wiley \& Sons; 1986. p.359-460.

60) Culbertson BM, Tiba A, Sang J, Liu YH. Synthesis, characterization and evaluation of new flourine-based dimethacrylates for formulating dental composites. Polymer Advanced Technology 1999; 10: 275-281.

61) Chen K, Wilkie CA, Vyazovkin S. Nanoconfinement revealed in degradation and relaxation studies of two structurally different polystyrene-clay systems. J Phys Chem B 2007; 111: 12685-12692. 